\title{
Management of Recurrent Aphthous Stomatitis Major in a Bipolar Affective Disorder Patient with Food Allergy
}

\author{
Nurina Febriyanti Ayuningtyas, ${ }^{1}$ Azimatul Karimah, ${ }^{2}$ Adiastuti Endah Parmadiati ${ }^{1}$ and Hening Tuti Hendarti ${ }^{1}$ \\ ${ }^{1}$ Department of Oral Medicine, Faculty of Dental Medicine, Universitas Airlangga, Surabaya, Indonesia \\ ${ }^{2}$ Department of Psychiatry, Faculty of Medicine, Universitas Airlangga, Surabaya, Indonesia
}

\begin{abstract}
This is the case of a 35-year-old female diagnosed by medical and psychiatric examinations as suffering from bipolar affective disorder and food allergy. Evident characteristic included mood swings. Her main complaint was extensive painful ulcer on the palate and lower lip. Current condition had caused her weight loss. Management included anamnesis, clinical and laboratory examinations, psychometrics, and referral to a psychiatrist. The dentist played an important role in identifying recurrent aphthous stomatitis and in the optimal and comprehensive treatment of the patient through multidisciplinary assessment.
\end{abstract}

Key Words: recurrent aphthous stomatitis, food allergy, bipolar affective disorder

\section{INTRODUCTION}

The oral mucosa can be highly reactive to psychological influences. Psychological disorders are characterized by physiological changes that originate, at least in part, from emotional factor. ${ }^{1}$

Bipolar affective disorder (BAD) is a mental illness, with mood swings characterized by episodes of extreme excitement and depression, including a latency period. This affects between $1 \%$ and $2 \%$ of the total population, with the same prevalence between men and women. ${ }^{1}$ Bipolar disorder is considered as a form of psychiatric illness that can be treated after being properly diagnosed through a combination of pharmacotherapy, psychotherapy, and counseling. ${ }^{2}$

Recurrent aphthous stomatitis (RAS) is the most common type of ulcerative disease of the oral mucosa, affecting $20 \%$ of the general population. Etiology is multifactorial - trauma, stress, hormonal, immunologic, drugs, etc. Psychological stress was assessed through questionnaire and results showed RAS patients exhibited higher stress levels, than the control group during their active episodes. ${ }^{3}$ RAS also occurs in people who have severe stress because when stress occurs, the immune system decreases causing tissue destruction. ${ }^{4,5,6}$

Studies reveal a correlation, albeit preliminary, between

Paper presented at the Joint Scientific Meeting in Special Care Dentistry, July 5, 2019, Amerta Room, 4th Floor, main campus of Universitas Airlangga, Surabaya,Indonesia.

Corresponding author: Nurina Febriyanti Ayuningtyas Department of Oral Medicine

Faculty of Dental Medicine Universitas Airlangga

J. Mayjen. Prof. Dr. Moestopo No. 47 Surabaya 60132 - Indonesia Email: nurina.ayoe@gmail.com
RAS and stress. Stress can trigger allergies and RAS, where there is an increase in cortisol levels or reactive oxygen species (ROS) initiating oral lesions. RAS is also associated with changes in the immune system, namely modifications that affect multiple immune system components that explain the role of stress that can trigger adaptive allergies without prior history. ${ }^{4,7}$ In some people, RAS is triggered by allergies induced by foods such as beef, cow's milk, chocolate, 
coffee, beans, cereals, almonds, strawberries, cheese, tomatoes, and wheat flour (containing gluten). ${ }^{8}$

Psychosomatic illnesses are physical illnesses that are aggravated by psychological factors, in this case recurrent apthous stomatitis triggered by bipolar affective disorder with food allergy. It is important to recognize the relationship between psychological factors and the condition of the oral cavity while treating oral psychosomatic disorders. An interdisciplinary approach involving the dentist, psychiatrist, and oral physician, with a long term follow up, is needed. ${ }^{3}$

The aim of this paper is to report on the management of recurrent aphthous stomatitis triggered by bipolar affective disorder with food allergy in a 35-year-old female patient in Dental Hospital Universitas Airlangga Surabaya.

\section{CASE REPORTS}

A 35-year-old female patient came to Dental Hospital Universitas Airlangga Surabaya with a chief complaint of painful ulcer on the palate and lower lip of one month duration. The patient claimed that she suddenly felt pain on the palate and her lip since a month ago. No history of trauma was elicited. Patient had previously visited a doctor or health care center to check her condition a year ago when the same complaint persisted on the palate. At that time she lost $12 \mathrm{~kg}$ due to the painful ulcer which troubled her during eating: the current condition caused her a weight loss of $2 \mathrm{~kg}$. A year ago when the same complaint persisted, the doctor performed a biopsy and the result showed no malignancy. Patient claimed she had no systemic diseases. The ulcer appeared regularly on the upper gingiva and lower lip ( \pm every 2 months), but the most severe in terms of pain and size, was a year ago and during this current condition. No remarkable findings on extra-oral examination was found, whereas the intra-oral examination found ulceration of the palate and left lower lip, measuring $1.5 \times 1$ and $1 \times 2 \mathrm{~cm}$, yellowish-white and surrounded by a reddish area (Figure 1). The working diagnosis for this case was major recurrent aphthous stomatitis with a differential diagnosis of Behcet Syndrome. Patient signed an informed consent and agreed to get treatment from our dental hospital. Symptomatic therapy consisted of mouthwash with chlorine dioxide was done. Patient was referred for blood tests.

Patient visited five days later and reported that the ulcer was less painful, except during meals. Patient reported to have used the medication regularly. No disorder on extra-oral examination was found. In the intra-oral examination, the clinical appearance was the same as in the previous visit so that we ruled out Behcet Syndrome as differential diagnosis. Blood tests showed normal level of hemoglobin A1c (HbA1c), low levels of hemoglobin, lymphocyte, and aspartate transaminase (AST) and high levels of eosinophil, monocyte, neutrophil, erythrocyte sedimentation rate, alanine transaminase (ALT), blood urea nitrogen (BUN), creatinine and Imunoglobulin E (IgE). Previous symptomatic therapy was stopped and changed with a new prescription triamcinolone acetonide $0.1 \%$ in orabase paste because the patient complained that pain was still present when eating. The working diagnosis of this case was changed to allergic stomatitis. Previous symptomatic therapy was continued and the patient was referred to an Ear, Nose and Throat (ENT) specialist for a Prick test.

Patient came back sixteen days since the first visit. Based from the prick test results, the patient received loratadine prescription from the ENT specialist. The patient reported that the pain had diminished and that the drug had been used as prescribed. The patient complained that her right cheek appeared swollen, and that new ulcerations developed in the right buccal mucosa and ventral tongue. Patient had been advised to avoid foods that are likely to be allergens according to the results of the prick test. Prick test result showed positive result for dust, dog and cat feather, kapok,
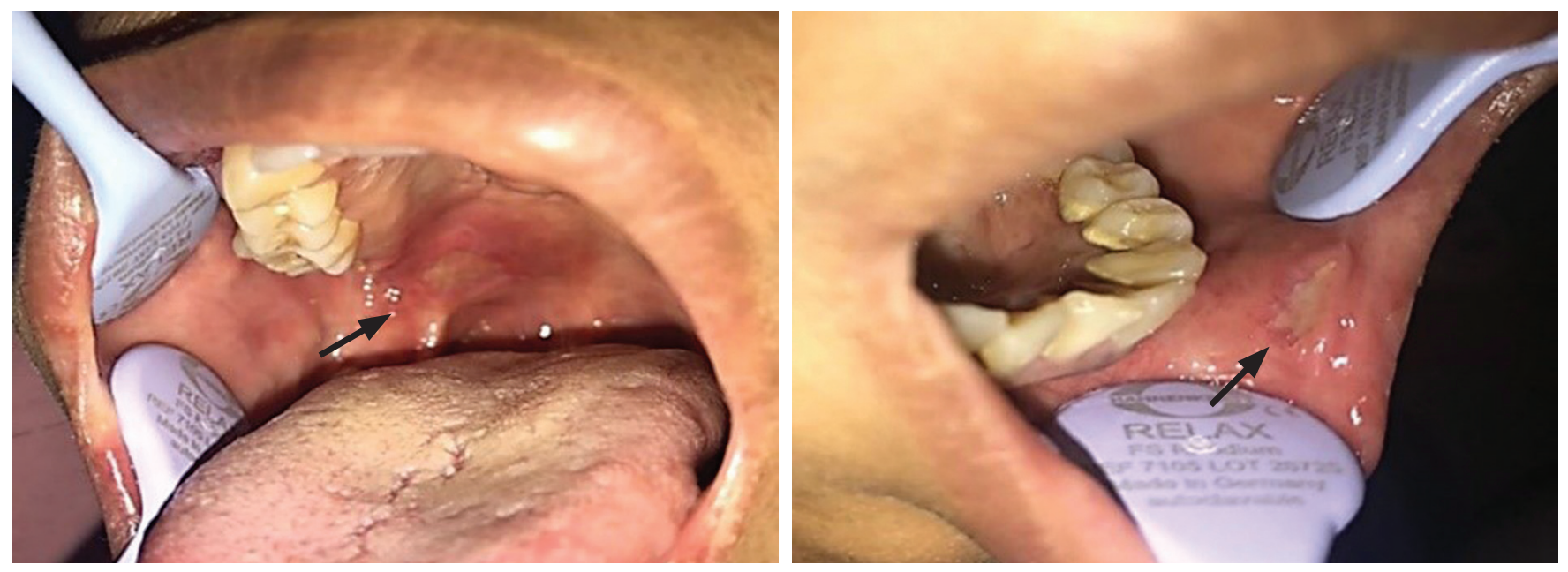

Figure 1. Ulcer on the palate and labial mucosa, $1.5 \times 1 \mathrm{~cm}$ and $1 \times 2 \mathrm{~cm}$, white surrounded by erythematous area, with clear border, irregular, painful. 

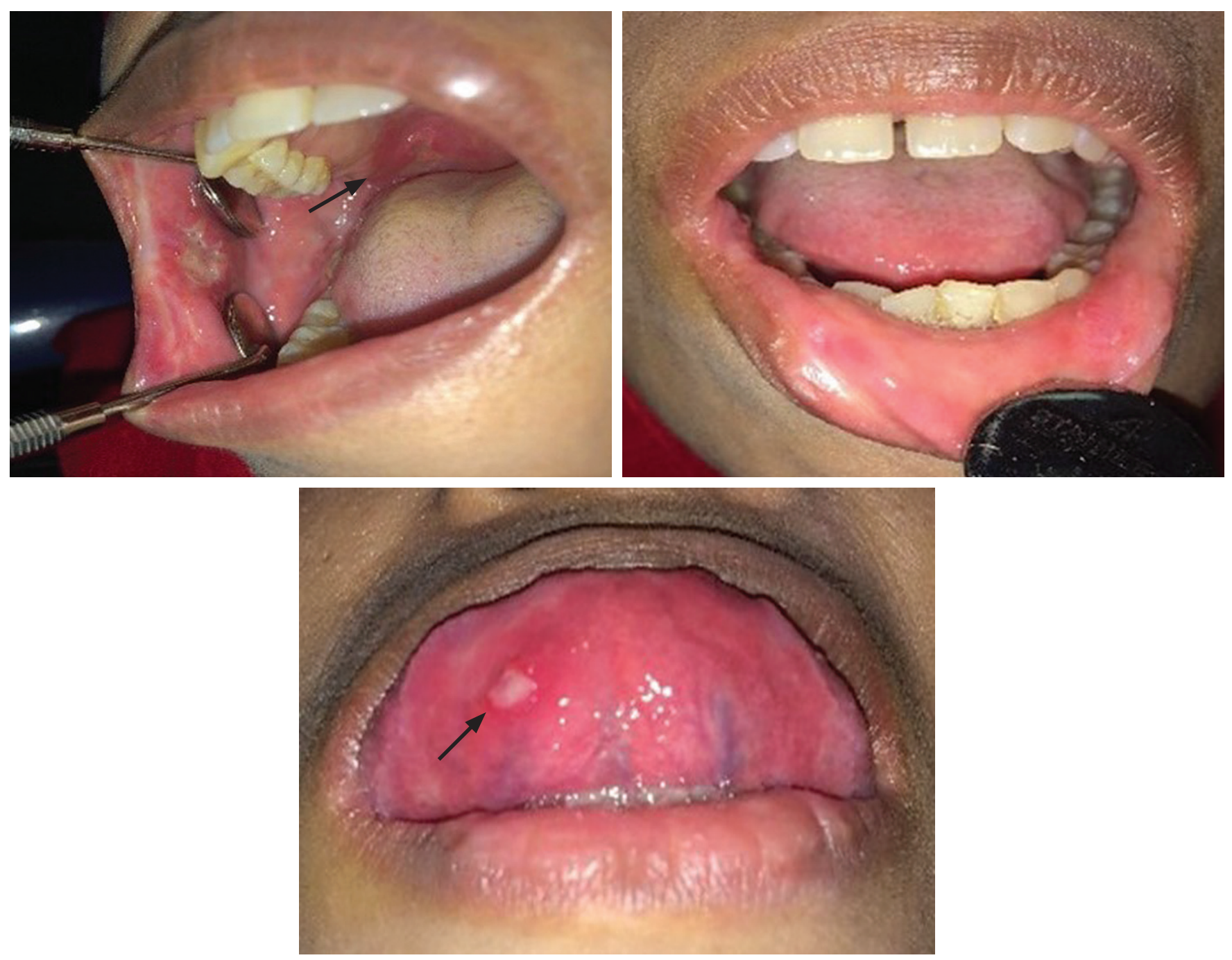

Figure 2. Ulcer on the labial mucosa heal, leaving ulcer on the palate, buccal mucosa and ventral tongue $0.5 \times 1.5 \mathrm{~cm}, 1.5 \times 1.5 \mathrm{~cm}$ and $\varnothing 2 \mathrm{~mm}$, white surrounded by erythematous area, clear border, irregular, painful.

beef, and duck white egg yolk. Even though patient had avoided foods that were likely to be allergens, new ulcers were still observed (Figure 2).

On follow up visit, patient reported to have consumed food that were allergenic according to the prick test results. The patient related to us while crying that she had a lot of thoughts and had family problems. Based on this, the questionnaire Depression Anxiety Stress Scales 42 (DASS 42) was filled out. There were no complaints of new ulcers. DASS results showed depression score of 17 (moderate), anxiety score of 18 (severe), and stress score of 27 (severe). On objective examination, ulcerations of the palate were still seen but were smaller in size, and facial asymmetry and ulceration in the right buccal mucosa and ventral tongue persisted. The working diagnosis of this case was major recurrent aphthous stomatitis with psychological stress and allergies. Previous symptomatic therapy was continued. Referral to psychiatric specialists for counseling was made.
During follow up visit at thirty nine to ninety six days since the first visit, patient was able to take a nap, and felt relax after the counselling session with the psychiatrist and having consumed the medication prescribed by psychiatrist. A new ulcer on the tongue was observed. Patient was diagnosed to have bipolar affective disorder according to ICD10 criteria (F31.3), current episode mild or moderate depression with marriage problem and was prescribed fluoxetine, clobazam, and risperidone. On objective examination days after the psychiatric session, ulcerations of the palate and the buccal mucosa were still present but were decreased in size, and facial asymmetry had decreased (with decreased facial swelling), but a newulceration on dorsal tongue was seen (Figure 3). Follow-up to psychiatry and continued taking medication from psychiatry department were advised. Extra-oral and intra-oral objective examination appeared normal during the patient's last consultation at ninety six days since the first visit (Figure 4). 

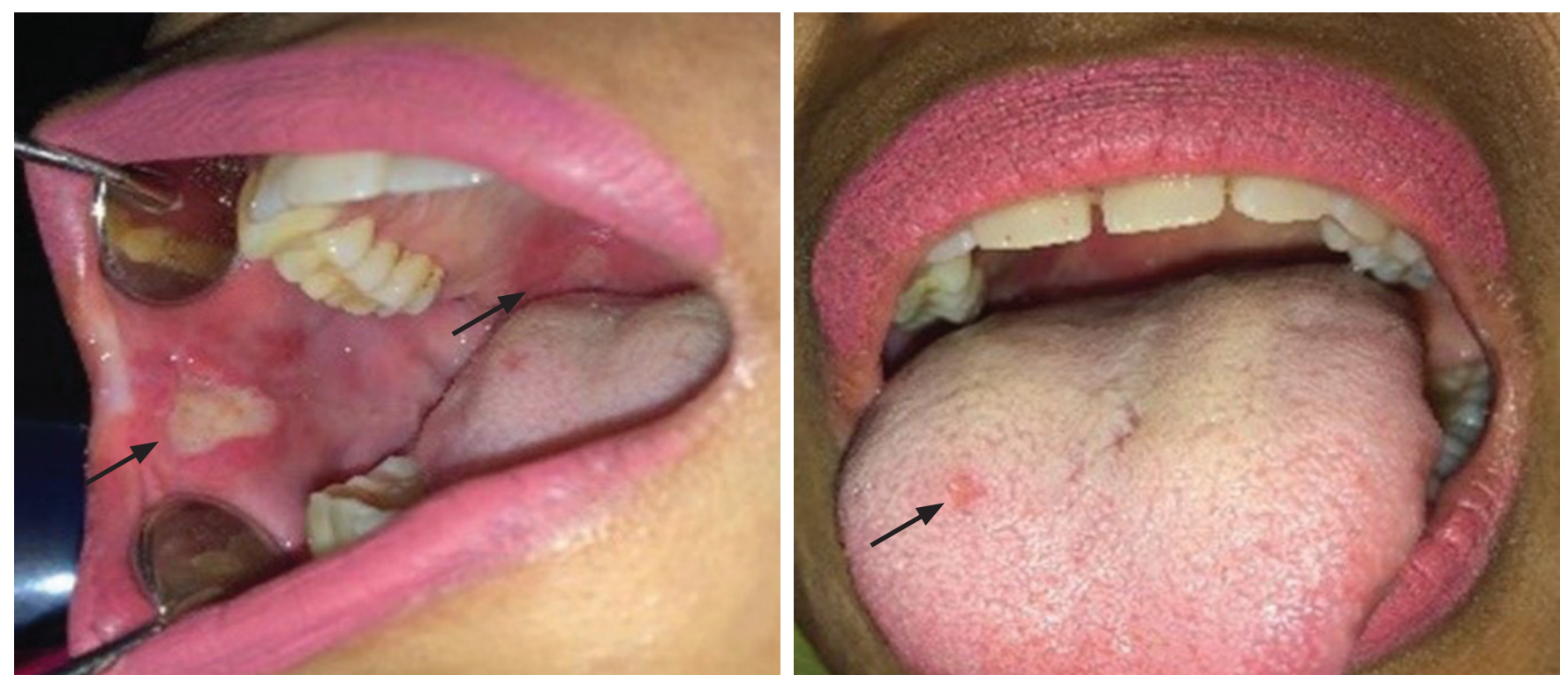

Figure 3. Ulcer on the palate, buccal mucosa and ventral tongue $1 \times 1 \mathrm{~cm}, 1 \times 1 \mathrm{~cm}$ and $1 \times 2 \mathrm{~mm}$, white surrounded by erythematous area, clear border, irregular, painful.
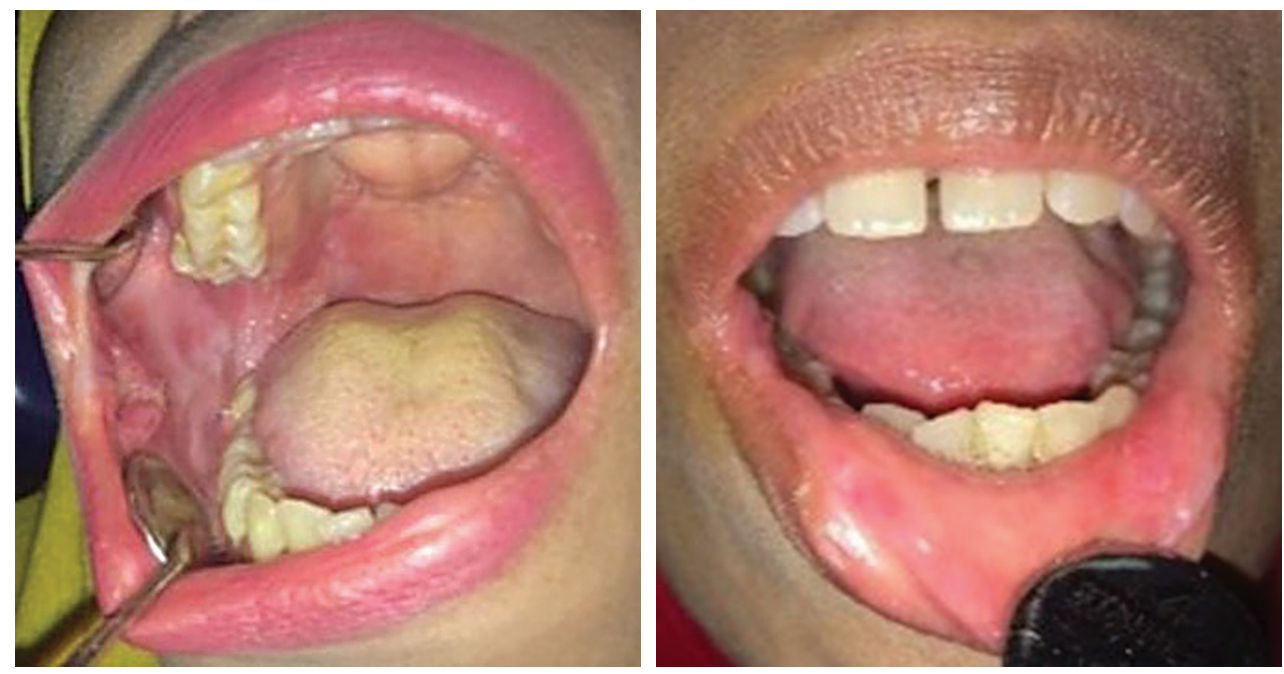

Figure 4. Ulcer heals.

\section{DISCUSSION}

One factor described to be potentially associated with exacerbation of recurrent aphthous stomatitis (RAS) is stress. According to some authors, stress is more likely to trigger episodes and recurrences rather than affect the duration. Furthermore, stress is considered one of the causes of RAS. ${ }^{9,10}$

Stress can be psychological stress and physical stress; this patient presented mainly with psychological stress, with additional physical stress. ${ }^{11}$ Stressors often occur from interactions with family, school environment or workplace. Stress can be characterized by an imbalance between the body's needs and the body's capacity to deal with a stressor, ${ }^{12}$ as in this case of a 35-year-old woman who led a daily life as a catering entrepreneur and was responsible as a single family income provider as the husband did not have a steady income, on top of marital problems since 10 years ago. ${ }^{7}$ Based on the duration and intensity of the stress experienced, the patient had repeated chronic stress.

Instruments for measuring stress levels, which use questionnaires, include the Depression Anxiety and Stress Scale-42 (DASS-42), which has admirable psychometric properties, and has been found to be reliable and valid among tested populations. ${ }^{13,14}$

Persistent anxiety problems cause changes in the HPA axis thereby increasing cortisol levels. ${ }^{9}, 10$ Studies show that long-term stress is associated with changes in brain structure and function, causing dysregulation in the body's 
responsive stress system by providing adequate cortisone protection. When stress becomes chronic, there are more immune reactions in the body in the form of hypersensitivity which further lead to more leukocyte recruitment at the antigen contact site and a worsening inflammatory response. In this way, the effects of stress on the endocrine system cause modulation of the immune system eventually leading to the development of psychosomatic disorders. The interaction between the sympathetic nervous system and the immune system during periods of stress causes vasodilation in the peripheral area. Furthermore, it causes an increase in the migration of dendritic cells as part of a hypersensitivity reaction. ${ }^{15}$

In the humoral response, the level of salivary $\operatorname{IgA}$ in patients with RAS shows an increase in the acute period and decreases in the period of regression and healing. In addition to $\operatorname{IgA}$, there is an increase in $\operatorname{IgG}$ and IgM levels. These changes can lead to pathological conditions in the mucosal epithelial cells of the oral cavity, so that epithelial cells are more sensitive to stimulation. ${ }^{16}$

Many reported allergic incidents due to the severity of stress. High eosinophil results were found which lasted longer in responding to allergies. ${ }^{7}$ This is in accordance with complete blood examination results that show an increase in eosinophil count. An increase in eosinophils is a sign of an allergic reaction. ${ }^{17}$

After a complete peripheral blood examination, it was found that eosinophil and $\operatorname{IgE}$ were increased and the patient was referred for skin prick test. The results obtained were allergens from house dust, dog hair, cat fur, beef, duck egg white, and kapok. Based on the patient exposure, the allergy was due to beef.

Red meat allergy is a tick-associated hypersensitivity reaction. This disease is caused by IgE-mediated responses directed against galactose-a-1,3- galactose (a-gal), a carbohydrate produced by all mammals except humans and some nonhuman primates and that is also found in tick saliva. The unusually long delay in symptom onset (mean time 7.1 years), nonspecific symptoms, and uncertain prevalence of red meat allergy can make this diagnosis challenging. ${ }^{18,19}$

Clinically the occurrence of stomatitis is a consequence of the destruction of the epithelium due to eosinophil degranulation. In type 1 hypersensitivity reactions, the number of eosinophils increases due to stimulation of IL-5 cytokines and eotaxins released by histamine. Eosinophils which infiltrate the tissues increase and undergo cytolytic processes which release toxic proteins such as Major Basic Protein (MBP), Eosinophil Cationic Protein (ECP) and Eosinophil-Derived Neurotoxin (EDN). This granular protein is highly toxic to tissues and can cause damage to epithelial cells. So that the degranulation process of eosinophils has a role in the mechanism of ulcer formation in the mucosa. In addition to toxic proteins, eosinophils also produce pro-inflammatory cytokines such as TNF- $\alpha$ which also play a role in tissue damage. In recent studies, eosinophils can also interact with fibroblasts and endothelial cells by inhibiting the synthesis of Transforming Growth Factor (TGF) $\alpha$ and $\beta$ thereby slowing the ulcer healing process. ${ }^{20-23}$

This patient was diagnosed to have affective bipolar disorder with somatic symptom by a psychiatrist based on the consideration that the patient had changes in mood characterized by episodes of extreme excitement and depression, among which there was a latency period.

Based on the history, clinical examination, and laboratory tests, the final diagnosis in this case was Major Type Recurrent Aphthous Stomatitis in Affective Bipolar Patient accompanied by food allergy. This is based on the consideration that in these patients even after avoiding allergens new ulcers still arise, leading to the main etiological possibility of psychological stress which can alter the immune system and body tissues including increasing the risk of allergies and reducing mucosal resistance.

Therapy given to the patient was a topical steroid preparation containing triamnicolone acetonide which is a medium-potential, intermediate-acting corticosteroid. The administration of triamcinolone acetonide was to suppress the inflammatory process and accelerate the process of healing lesions. ${ }^{24,25}$ Before the prick test, steroidcontaining drugs were stopped and replaced with topical anti-inflammatory drugs given to patients containing chlorine dioxide which has the ability as an antiseptic and for epithelial regeneration. ${ }^{26}$ After a firm diagnosis due to allergic involvement, the patient received a prescription for loratadine tablets from an ENT specialist. Loratadine role was as an antihistaminic. ${ }^{27}$

In addition, the patient was prescribed medication by psychiatrist which were fluoxetine, clobazam, and risperidone. Fluoxetine is a selective serotonin reuptake inhibitor (SSRI) antidepressant drug used to treat depression, obsessive compulsive disorder (OCD), bulimia, and panic attacks. ${ }^{28}$ Risperidone is a medication for schizophrenia, bipolar disorder, depression, and irritability associated with autism. Risperidone is a second generation atypical antipsychotic used to treat schizophrenia and bipolar disorder. ${ }^{29}$ Clobazam belongs to the anticonvulsant group and is used to treat epilepsy and seizures. ${ }^{30}$

According to the literature, the prognosis for $\mathrm{BAD}$ is considered relatively favorable. During the dental treatment, the mood swings and recurrent episodes of depression, which is characteristic of the disorder, was evident in this patient and contributed to increase her anxiety and recurrence of somatic symptom, in this case intra-oral ulcer formation. The dentist accounted for identifying the factors causing anxiety and fear and implemented different strategies of management of behavior to minimize them. ${ }^{1}$

\section{CONCLUSION}

Treatment of a BAD patient requires extra care with psychosocial intervention. Long-term care is needed to 
establish greater connections between the dentist and the patient. Strategies must be developed to continuously motivate patients.

RAS is an inflammation of the oral cavity that often occurs. RAS can be triggered by several factors, one of which is psychological stress which can change the immune system and body tissues including increased risk of allergies and reduced mucosal resistance. Elimination of trigger factors is the main therapy for RAS to prevent recurrence and reduce frequency.

\section{Statement of Authorship}

All authors participated in data collection and analysis, and approved the final version submitted.

\section{Author Disclosure}

All authors declared no conflict of interest.

\section{Funding Source}

None.

\section{REFERENCES}

1. Rossetti E, Kruchinski de Azevedo E, Zanini BE, Lemes VC, Brancher JA, Torres MF, et al. Oral rehabilitation in a patient with bipolar affective disorder: clinical case report. Réseau Recherche en Santé Buccodentaire et osseuse. 2015; 12(3):330-3.

2. Swartz HA, Swanson J. Psychotherapy for bipolar disorder in adults: a review of the Evidence. Focus (Madison). 2014; 12(3):251-66.

3. Patil PB, Savalagi AG. Psychosomatic disorders of the oral cavity-a review. American Journal of Oral Medicine and Radiology. 2015; 2:96-102.

4. George S, Baby Joseph B. A study on aphthous ulcer and its association with stress among medical students of an Indian medical institution. Int J Contemp Med Res. 2016; 3(6):1692-5.

5. Junhar MG, Suling PL, Supit ASR. Gambaran Stomatitis Aftosa Rekuren dan Stres pada Narapidana Di Lembaga Pemasyarakatan Kelas II B Bitung. Jurnal e-Gigi. 2015; 3(1):1-8.

6. Ernawati DS, Soebadi B, Radithia D. Human-leukocyte antigen typing in Javanese patients with recurrent aphthous stomatitis. Dental Journal. (Majalah Kedokteran Gigi). 2010; 43(1):26-30.

7. Dave ND, Xiang L, Rehm KE, Marshall GD Jr. Stress and allergic diseases. Immunol Allergy Clin North Am. 2011; 31(1):55-68.

8. Tarakji B, Baroudi K, Kharma Y. The effect of dietary habits on the development of the recurrent aphthous stomatitis. Niger Med J. 2012; 53(1):9-11.

9. Karthikeyan P, Aswath N. Stress as an etiologic co-factor in recurrent aphthous ulcers and oral lichen planus. J Oral Sci. 2016; 58(2):237-40.

10. Kunikullaya UK, Kumar MA, Ananthakrishnan V, Jaisri G. Stress as a cause of recurrent aphthous stomatitis and its correlation with salivary stress markers. Chin J Physiol. 2017; 60(4):226-30.
11. Montoro J, Mullol J, Jáuregui I, Dávila I, Ferrer M, Bartra J, et al. Stress and allergy. J Investig Allergol Clin Immunol. 2009; 19 Suppl $1: 40-7$.

12. Sen S, Saha A, Singh T. Effect of psycosomatic factors in oral diseases. Int J Clin Prev Dent. 2014; 10(2):51-4.

13. Tan KC, Chan GC, Eric H, Maria AI, Norliza MJ, Oun BH, et al. Depression, anxiety and stress among patients with diabetes in primary care: A cross-sectional study tan lie. Malays Fam Physician. 2015; 10(2):9-21.

14. Ramli M, Rosnani S, Aidil Faszrul AR. Psychometric Profile of Malaysian version of the Depressive, Anxiety and Stress Scale 42-item (DASS-42). MJP Online Early. 2012; 1:7.

15. Jain K, Mehendiratta M, Kardam P, Yadav J, Jindal DG. Crosstalk between Mind and Oral Cavity: An Insight into Pathogenesis, Classification, Presentation and Management of Oral Psychosomatic Disorders. Int Neuropsychiatr Dis J. 2016; 5(2):1-12.

16. Ślebioda Z, Szponar E, Kowalska A. Etiopathogenesis of recurrent aphthous stomatitis and the role of immunologic aspects: Literature review. Arch Immunol Ther Exp. (Warsz). 2014; 62(3):205-15.

17. kemenkes. (PDF) Pedoman Interpretasi Data Klinik. 2011; 4-71.

18. Brestoff JR, Zaydman MA, Scott MG, Gronowski AM. Diagnosis of red meat allergy with antigen-specific IgE tests in serum. J. Allergy Clin Immunol. 2017; 140(2):608-610.e5.

19. Jackson WL. Mammalian meat allergy following a tick bite: a case report. Oxf Med Case Reports. 2018; 2018(2): omx098.

20. Forbes Murase T, Yang M, Matthaei KI, Lee JJ, Lee NA, E et al. Immunopathogenesis of experimental ulcerative colitis is mediated by eosinophil peroxidase. J Immunol. 2004; 172(9):5664-75.

21. Balcheva M, Kisselova A. Food allergy and oral allergy syndrome. Part II. A review. J IMAB. 2013; 19(4):374-376.

22. Raviteja YS, Kundana I, Triveni T. Eosinophilic ulcer of the oral mucosa. Int J Dent Med Res. 2015; 1(5):112-5.

23. Ghosh S, Nambiar S, Patil S, Haragannavar V, Augustine D, Sowmya $\mathrm{SV}$, et al. Allergic and immunologic response of the oral mucosa: An overview. Int J Clin Dent Sci. 2016; 6:1-7.

24. Belenguer-Guallar I, Jiménez-Soriano Y, Claramunt-Lozano A. Treatment of recurrent aphthous stomatitis. A literature review. J Clin Exp Dent. 2014; 6(2):168-74.

25. Hamishehkar H, Nokhodchi A, Ghanbarzadeh S, Kouhsoltani M. Triamcinolone acetonide oromucoadhesive paste for treatment of aphthous stomatitis. Adv. Pharm. Bull. 2015; 5(2):277-82.

26. Widagdo AK, Herawati D, Syaify A. Aplikasi Chlorine Dioxide Gel Pada Periodontitis Kronis Paska Kuretase. Jurnal Kedokteran Gigi. $2015 ; 3,265-70$.

27. Church DS, Church MK. Pharmacology of antihistamines. World Allergy Organ J. 2011; 4(3 Suppl):S22-7.

28. Harahap MA. Penderita Gangguan Suasana Perasaan Episode Depresif. 2010; 29-30.

29. Madaan V, Bestha DP, Kolli V, Jauhari S, Burket RC. Clinical utility of the risperidone formulations in the management of schizophrenia. Neuropsychiatr Dis Treat. 2011; 7:611-20.

30. Pernea M, Sutcliffe AG. Clobazam and its use in epilepsy. Pediatr Rep. 2016; 8(2):6516. 